\title{
Background soundscapes influence the perception of ice-cream as indexed by electrophysiological measures
}

\author{
Yun $\mathrm{Xu}^{\mathrm{a}}$, Nazimah Hamid ${ }^{\mathrm{a}}$, Daniel Shepherd ${ }^{\mathrm{b}}$, Kevin Kantono ${ }^{\mathrm{a}}$, \\ Stephen Reay ${ }^{\mathrm{c}}$, Guillaume Martinez ${ }^{\mathrm{d}}, \&$ Charles Spence ${ }^{\mathrm{e}}$
}

${ }^{a}$ Department of Food Science, Auckland University of Technology, Private Bag 92006, Auckland, 1142, New Zealand

b Department of Psychology, 90 Akoranga Drive, Auckland University of Technology, Private Bag 92006, Auckland 1142, New Zealand

${ }^{\mathrm{c}}$ School of Art and Design, 34 St Paul Street, Auckland University of Technology, Private Bag 92006, Auckland 1142, New Zealand

d Agrocampus Ouest - Cursus Agroalimentaire, 65 Rue de Saint-Brieuc, Agrocampus Ouest Rennes 35042, France

e Crossmodal Research Laboratory, Department of Experimental Psychology, Anna Watts Building, University of Oxford, Oxford, OX2 6GG, UK

*Corresponding author email: nhamid@aut.ac.nz

Keywords: Chocolate ice-cream; soundscapes; TDS; electrophysiological measurements; emotion 


\begin{abstract}
Listening to specific soundscapes can influence multisensory flavour perception. In the present study, changes in people's perception of the flavour of ice-cream were tracked over time as they listened to a café soundscape, and when this soundscape was overlaid with either bird, machine, or forest soundscapes. In addition, emotions and electrophysiological measures were recorded in order to help understand any changes in taste/flavour perception. The results of Temporal Dominance of Sensation (TDS) analysis revealed that cocoa was dominant early in the consumption episode while listening to the control café soundscape. Sweetness and creaminess were dominant at the start of the consumption episode while listening to the café-forest soundscape. Creaminess was dominant at the start of the consumption episode while listening to the cafe-bird soundscape. Bitterness was perceived at the end of the consumption period while listening to the café control and café-machine soundscapes. These findings demonstrate the crossmodal influence of audition on perception in the chemical senses. As expected, negative emotions were significantly higher when listening to the machine soundscape, while positive emotions were significantly higher when listening to café-forest and café-bird soundscapes. Evaluating ice-cream while listening to the café-machine soundscape evoked negative emotions associated with bitterness and creaminess, that were also associated with increased heart rate (HR) and respiration rate (RESP). When listening to the café-forest soundscape, ice-cream was associated with sweetness, and positive emotions (e.g., love, satisfaction, happiness, amusement and enjoyment). This might have led to increased blood volume pulse (BVP) amplitude, which is itself indicative of a relaxed state. Enhancing eating experiences by means of atmospheric soundscapes that are designed specifically to accentuate specific aspects of multisensory taste/flavour perception is currently an area of interest in the food sciences literature and will likely lead to future commercial applications.
\end{abstract}




\section{Introduction}

There is increasing evidence that background soundscapes/noise can influence people's perception of food and drink (Spence, 2014). A growing body of empirical research now shows that multisensory flavour perception sometimes changes when people listen to music (Stafford, Fernandes, \& Agobiani, 2012), instrumental sounds (e.g., the sound of a piano note \& brass instruments (Crisinel, 2010), aircraft cabin noise (Rahne, Köppke, Nehring, Plontke, \& Fischer, 2018), and high-pitched soundscapes (Crisinel et al., 2012). In addition, increased ratings of the crispness, crunchiness, and freshness of food were reported when participants listened to the live feedback of amplified crisps sounds above $2 \mathrm{kHz}$ (Zampini \& Spence, 2004), freshness of potato crisps were enhanced by the rattling of a bag of crisp (Spence, Shankar, \& Blumenthal, 2011), and bite sounds increased perception of crispiness and hardness of apples (Demattè et al., 2014), and loud white noise increased perception of texture attributed to sounds (e.g., crunchiness) compared to a silent condition (Woods et al., 2011). Elsewhere, it has been reported that odour pleasantness, discrimination, and sensitivity decreased when people listened to incongruent sounds/soundscapes (Seo \& Hummel, 2010), as well as verbal material (e.g., listening to an audio book) and/or party noise (Seo, Gudziol, Hähner, \& Hummel, 2011; Seo, Hähner, Gudziol, Scheibe, \& Hummel, 2012). Soundscapes have also been shown to influence ratings of sweetness (Carvalho, Wang, van Ee, Persoone, \& Spence, 2017; Crisinel, 2010; Crisinel et al., 2012; Rahne et al., 2018; Stafford et al., 2012), bitterness (Carvalho et al., 2017; Crisinel, 2010; Crisinel et al., 2012), sourness (Crisinel, 2010; Rahne et al., 2018), crunchiness (Woods et al., 2011), odour pleasantness (Seo \& Hummel, 2010), odour sensitivity (Seo et al., 2012), and odour discrimination (Seo et al., 2011).

A number of studies have concluded that listening to natural and urban soundscapes can evoke short-term intense feelings of positive (e.g., joy) and negative emotions (e.g., sad) (Krzywicka \& Byrka, 2017; Özcan \& van Egmond, 2012). This may impact affective states, taken to be psychophysiological constructs varying along the dimensions of valence, arousal, and dominance (Medvedev, Shepherd, \& Hautus, 2015). Previous research has established that pleasantness and relaxation are linked to listening to natural soundscapes such as the ocean and bird song (Krzywicka \& Byrka, 2017; Medvedev et al., 2015). Other studies have demonstrated the association of negative emotions such as unpleasant, annoyance, fear, and sad when listening to machine soundscapes (Özcan \& van Egmond, 2012), railway and road traffic noises (Urban \& Máca, 2013), turbine noise (Pedersen \& Waye, 2007), public transport noise (Paunović, Belojević, \& Jakovljević, 2014), and dichotic situations in which one ear is presented with a news story, while music is presented to the other ear (Stafford et al., 2012). Furthermore, studies have found that the arousal ratings increase, though not significantly, when listening to natural soundscapes like bird song and ocean soundscape as compared to construction and road traffic soundscapes (Medvedev et al., 2015). In turn, higher dominance ratings were associated with listening to urban soundscapes such as construction, motorbike, airplane, and road traffic soundscapes (Medvedev et al., 2015). To date, there have been relatively few studies that have investigated the effect of soundscapes during the consumption of food upon consumers' affective states. Kantono, Hamid, Shepherd, Lin, Yoo, et al. (2016) reported that listening to a positively-valenced café soundscape increased the rated pleasantness of chocolate gelati compared to bar and fast food soundscapes. In contrast, listening to a bar soundscape which was rated as most arousing and dominant resulted in gelati being perceived as the least pleasant compared to other soundscape conditions (i.e., café and fast 
food soundscapes). The authors further demonstrated that ratings of the pleasantness of gelato were influenced by the psychoacoustical characteristics and affective ratings associated with the soundscapes. Numerous studies have attempted to explain how it is that different soundscapes like nature soundscapes (Krzywicka \& Byrka, 2017; Medvedev et al., 2015; Xu et al., 2019), urban soundscapes (Eifert, Craill, Carey, \& O'Connor, 1988; Kantono, Hamid, Shepherd, Lin, Yakuncheva, et al., 2016; Paunović, Belojević, \& Jakovljević, 2013; Paunović et al., 2014; Urban \& Máca, 2013), and even music (Carvalho et al., 2017; Crisinel, 2010; Kantono et al., 2018; Wang $\&$ Spence, 2018) can increase or decrease positive and negative emotions, as well as affective judgments of valence, arousal, and dominance.

Researchers have studied the effects of soundscapes on physiological signals such as respiration rate (RESP), blood volume pulse (BVP), blood pressure (BP), skin conductance (SC), and heart rate (HR). Annoying soundscapes (i.e., such as noise) have been found to influence measures of HR, SC, RESP, systolic BP, and diastolic BP. Heart rate has been shown to increase significantly while listening to noisy residential soundscapes (Belojevic, Jakovljevic, Paunovic, Ilic, \& Stojanov, 2008), urban soundscapes (Laumann, Garling, \& Stormark, 2003), pleasant soundscapes (Shepherd, Hautus, Lee, \& Mulgrave, 2014), music (Eifert et al., 1988), bird or ocean soundscapes (Medvedev et al., 2015), highly-arousing noises (Gomez \& Danuser, 2004), and sad movies (Kreibig, Wilhelm, Roth, \& Gross, 2007). A significant increase in SC has been documented when people listened to irrelevant tones during task performance (Frith \& Allen, 1983), loud noise (Alvarsson, Wiens, \& Nilsson, 2010), construction and road traffic soundscapes (Medvedev et al., 2015), highly-arousing music (Gomez \& Danuser, 2004), and when watching sad movies (Kreibig et al., 2007). In contrast, no significant increase was reported for RESP measures when listening to noise (Gomez \& Danuser, 2004). Time-domain respiratory measurements were further found to change with the type of music clips, with the longest mean breath length with sad music, and the shortest with happy music (Etzel, Johnsen, Dickerson, Tranel, \& Adolphs, 2006). Furthermore, researchers have also demonstrated significant increases in systolic BP and diastolic BP while listening to noisy residential and kindergarten soundscapes (Belojevic et al., 2008), railway noise (Dratva et al., 2011), and the noise associated with public transport (Paunović et al., 2013).

Limited studies have been carried out to determine how physiological signals such as BVP, RESP, $\mathrm{HR}$, and $\mathrm{SC}$ are related to the emotions that are perceived by individuals while listening to soundscapes and music. Etzel et al. (2006) reported a significant decrease in RESP rate in relation to sadness compared to the positive emotion of happiness when listening to music. Meanwhile, Salimpoor, Benovoy, Larcher, Dagher, and Zatorre (2011) reported significant increases in RESP and HR when listening to music that induced pleasurable chills as compared to neutral music that was rated as less pleasant. On the other hand, BVP significantly decreased when listening to music that evoked intensely pleasurable emotion compared to neutral music. However, none of these studies involved individuals consuming food while listening to the different soundscapes. Meanwhile, a recent study by Kantono et al. (2019) demonstrated that BVP amplitude was positively correlated with disgust, and amusement, and negatively correlated with satisfaction and disappointment, when ice-cream was consumed while listening to music that varied in liking.

Having highlighted the gap in the existing literature, more research is clearly needed in order to describe how background soundscapes influence food perception, emotions, and electrophysiological measures. Hence the aim of the present study was to document perceptions of ice-cream consumed under different café soundscape conditions overlaid with either bird, 
machine, or forest soundscapes. The bird and forest soundscapes were chosen in this study as representative examples of natural soundscapes are reported to evoke positive valence response, while machinery repeating has been reported to evoke a negatively-valenced response (Gomez \& Danuser, 2004). Our hypothesis was that the overlaying of these soundscapes onto the baseline of a café environment soundscape with chatter and the clattering of plates in the background would influence people's multisensory perception of ice-cream. Importantly, the present study also explores how emotions and electrophysiological measures may help to explain any such changes in sensory perception. 


\section{Materials and methods}

\subsection{Ethics statement}

The current study was approved by the Auckland University of Technology Ethics Committee (AUTEC 12/79). The participants all gave their written informed consent prior to taking part in the study.

\subsection{Participants}

Forty-five participants (15 males, 30 females) between the ages of 16 and 37 years took part in the study $\left(M_{\text {age }}=22.8\right.$ years, $S D=3.4$ years $)$. This number of participants resulted in a statistical power of 0.95, using a Cohen's $d$ effect size of 0.8 derived from a pilot study (Aguinis \& Harden, 2009). All of the participants were either students or staff from the Auckland University of Technology. The participants were recruited online by means of an advertisement posted on social media networks (i.e., Facebook and Instagram) and informally by word-of-mouth. Participants were excluded if they were smokers, or reported any hearing loss, eating disorders, or other health problems that may have interfered with their hearing, taste, or sense of smell. All of the data was collected between 11:00 am and 1:00 pm, and participants were directed not to eat for the two hours prior to the study.

\subsection{Background noise stimuli}

Four soundscapes were used in the study. They included the background soundscapes of a cafe environment (control), and this environment soundscape was overlaid with bird sounds (café-bird), forest sounds (café-forest), and machine sounds (café-machine) to create overlaid soundscapes. The soundscapes used in this study were purchased from Soundsnap (https://www.soundsnap.com/). Audio stimuli used in this study can be accessed through SoundCloud (https://soundcloud.com/jkevink/sets/cafe-soundscapes-fri). Each soundscape was played to each participant over a pair of Sennheiser Series HD 518 headphones (Sennheiser Electronics GmbH and Co. KG, Wademark, Germany) using a standard PC sound card. The order in which the various auditory stimuli were delivered was randomized and counterbalanced in order to minimize any order effects. The Root Mean Square amplitudes of the audio samples were standardized to an internal reference in order to achieve equivalent average sound pressure levels across all audio samples, and later scaled to $70 \mathrm{~dB}$ of sound pressure level (SPL), using a Brüel and Kjær sound meter (Brüel \& Kjær, Nærum, Denmark).

\subsection{Food stimuli}

The chocolate ice-cream samples were made up of $60 \%$ cream, $16 \%$ milk, $15.7 \%$ sugar, $8 \%$ cocoa powder, and $0.3 \%$ vanilla extract. An ICE-100 ice-cream and gelato maker (Cuisinart, America) was used to manufacture the chocolate ice-cream. A scoop of the ice-cream $(50 \pm 0.8 \mathrm{~g})$ was placed in individual portion cups (45 mm diameter) and frozen in a commercial-grade freezer 
(Fisher and Paykel, NZ) at $-18^{\circ} \mathrm{C}$ for at least 24 hours prior to serving to ensure sample consistency. Each ice-cream sample was served to participants under white light.

\subsection{Training}

The participants were trained according to the protocol described by Kantono et al. (2016b). In brief, they were emailed a link to a demonstration video showing how TDS worked before coming into the laboratory. Once they arrived at the laboratory, the concept of dominance was explained and was defined as the sensory sensations linked to the food stimuli that captured the observer's attention at any given moment in time. They were informed that dominance might switch once a new sensation was perceived (Labbe, Schlich, Pineau, Gilbert, \& Martin, 2009). The participants were also given basic instructions concerning what was expected of them when following onscreen prompts for TDS, emotion, and electrophysiological procedures as used in this experiment. At the end of the training session, the participants were required to carry out a practice trial in order to familiarise themselves with the different procedures involved in the experiment.

\subsection{TDS measurement}

TDS was obtained to measure the temporal perception of the flavour of ice-cream as described by Pineau et al. (2009). For this study, cocoa, milky, creamy, vanilla, roasted, sweet, and bitter were measured using buttons, coded as a binary response ( 0 when the attribute was not selected and 1 when selected). Detailed instructions were also provided to minimize any variation in the consumption behaviour of the participants. Following the concept of dominance, when one attribute representing a single sensation was selected, the other sensory attributes were automatically deselected. In addition, TDS-related best-practice was also implemented, this being: 1) short product evaluation time (20-40 s in duration); 2) consistent order of attributes, and; 3 ) diverse range of sensory attributes. For each eating environment soundscape, a TDS session lasted for 45 seconds. All sensory data acquisition was carried out using the FIZZ Acquisition software (v. 2.46b: Biosystemes, France).

\subsection{Emotion}

The emotional responses of participants were determined while listening to the different soundscapes using an unstructured $150 \mathrm{~mm}$ line scale anchored with the labels "none" and "extreme". These emotional responses were divided into two groups; positive (amusement, enjoyment, happiness, love, and satisfaction), and negative (anger, contempt, disappointment, and disgust; see Kantono et al., 2016b). Prior to the experiment, the participants were provided with definitions of these emotions in order to ensure that they understood them and used them consistently. Additionally, these definitions were also made available throughout the experiment. All emotion data acquisition was carried out using the FIZZ Acquisition software (v. 2.46b: Biosystemes, France). 


\subsection{Electrophysiological measurements}

The electrophysiological measures in this study were collected using medical-grade 24-bit hardware (NeXus 10) and software (Mind Media, Netherlands) with standard Ag/ $\mathrm{AgCl}$ electrodes. A standard three-lead configuration was adopted to obtain electrocardiogram measures, while skin conductance was measured from the $3 \mathrm{rd}$ and 4th digits (middle phalanx) of the non-dominant hand. Blood volume pulse was recorded using a photoplethysmograph attached the left index finger. Additionally, the participant's respiration rate was measured using a transducer belt transforming instantaneous mechanical tension into an electric signal. Prior to measurement, the sensors were cleaned to ensure effective adhesion to the sites, more precisely to the left and right side of the chest, to the right side of the stomach (ECG), and the fingers of the non-dominant hand (SC). The sensors were then placed carefully on the participant's body and the equipment functions were then verified using the BioTrace software. As soon as the verification procedure had been completed, the recording of the participants' heart rate (HR), skin conductance (SC), respiration (RESP), and blood volume pulsation (BVP) commenced. Participants were not allowed to move their non-dominant hand throughout the duration electrophysiological measurements was obtained.

Initially, a ten-minute baseline electrophysiological measurement was obtained in which participants were instructed to sit in an upright comfortable position. In the second phase of the study, the participants listened to the cafe (control) soundscape overlaid with bird (cafe-bird), forest (café-forest), and machine (café-machine) soundscapes (randomised and counterbalanced across participants using a Latin square design) while electrophysiological measurements were obtained. In the third and final phase of the study, electrophysiological measurements were obtained when participants consumed a spoonful chocolate ice-cream $(10.0 \pm 1.0 \mathrm{~g})$, either while listening the control soundscape or else the overlaid soundscapes, with each measurement period lasting for $45 \mathrm{~s}$. This was chosen as phasic electrodermal measures typically peak around 2-5 s after stimulus delivery with recovery occurring after $30 \mathrm{~s}$. Note that the recovery rate is dependent upon the participant's emotional state, and so an average of $45 \mathrm{~s}$ was calculated. All electrophysiological indices, including HR, were analysed at a rate of 32 data samples/s.

\subsection{Experimental procedure}

Three different measurements were collected in this study, which took up to eighty minutes to complete. For the first ten minutes, baseline electrophysiological measures were obtained while the participants were seated in the laboratory listening to each soundscape (and before they consumed the ice-cream). The participants were instructed to relax while the electrophysiological measurements were obtained for the baseline phase and were then given a five-minute break. Finally, participants' electrophysiological measures were obtained during ice-cream consumption while listening to different soundscapes over a period of 45-s.

TDS was used to determine the temporal evolution of flavour perception for the chocolate icecream over the course of a 45-s period. On-screen instructions were provided in order to minimise eating variation across soundscapes and participants. Participants placed a spoonful of ice-cream in their mouth and allowed it to melt for the first 14 seconds. They were then instructed to swallow 
it after $15 \mathrm{~s}$ had elapsed and continued to evaluate sensory sensations for up to $45 \mathrm{~seconds}$. When participants selected a scale that corresponded to a sensory attribute by clicking it, the soundscape automatically started and on-screen instructions concerning how to consume the gelato samples was presented to the participants. The participants were given a 5-min break to prevent possible fatigue between samples. Finally, after the TDS trial, the participants subjectively rated their emotions using an unstructured line scale anchored with "none" and "extreme".

\subsection{Data analysis}

\subsubsection{TDS curves}

TDS dominance curves were obtained to display the dominance ratings of all attributes over time using an in-built spline-based smoothing algorithm proprietary to the FIZZ software (Pineau et al., 2009). Temporal dominance curves represent the percentage of participants who identified the prescribed attribute as being dominant at a given point in time after the start of the trial (Pineau et al., 2009). TDS time was presented as standardized time (ST), and the data was converted to percentages $(0-100 \%)$. The significant $\left(\mathrm{P}_{\mathrm{s}}\right)$ and the chance $\left(\mathrm{P}_{0}\right)$ levels were determined from the panel curves, and calculated according to Pineau et al. (2009):

$$
\begin{gathered}
P_{0}=1 / p \\
P_{S}=P_{0}+1.645 \sqrt{\frac{P_{0}\left(1-P_{0}\right)}{n}}
\end{gathered}
$$

Where $\mathrm{P}_{0}$ is chance level, $\mathrm{p}$ is number of attributes, $\mathrm{Ps}$ is significance level, and $\mathrm{n}$ is the number of TDS observations (number of participant $\mathrm{x}$ replication). 


\subsubsection{TDS trajectory plots}

Principal component analysis (PCA) was carried out on the dominance rates of every dominant attribute over time while eating ice-cream, using XLSTAT (Version 2018.5) (Addinsoft, U.S.A). The PCAs provide a global representation of the trajectory of different soundscape conditions in relation to the evolution of each dominance in flavour perception based on the first and second principal components. The static points along this trajectory are determined by checking the cosine of the angle between a point along the trajectory and the attributes. The dominant flavour trajectories in each soundscape are explained by connecting the time points graphically (from the starting score $\left(\mathrm{t}_{0}\right)$ to the last score $\left(\mathrm{t}_{100}\right)$ point). The time points were $0 \%, 5 \%, 10 \% \ldots 100 \%$ of the TDS standardized time (Saint-Eve, Panouille, Capitaine, Deleris, \& Souchon, 2015), with a total of 21 standardized time points for each 45 -s soundscape condition.

\subsubsection{Emotional response to soundscapes}

A one-way repeated measures ANOVA (RM-ANOVA) was conducted in order to explore significant differences $(\alpha=.05)$ in emotions evoked by different soundscape stimuli. Tukey's multiple comparison tests with Bonferroni correction were carried out for analyses that reached statistical significance.

\subsubsection{Analysis of electrophysiological measures}

Average values of electrophysiological indices (i.e., BVP, RESP, SC, and HR) were calculated with reference to a ten-minute baseline measurement. The percentage change from the baseline was calculated according to Zhang et al. (2009):

$$
\text { Percentage change }(\%)=\frac{(\text { raw value }- \text { mean baseline value })}{\text { mean baseline value }} \times 100
$$

Repeated measures ANOVA was applied to the modified data in order to test the effect of soundscape conditions. Tukey post-hoc comparisons with Bonferroni correction were applied when significance was found. 


\subsubsection{Canonical Variate Analysis}

Canonical Variate Analysis (CVA) was performed on the perceptual, emotion, and electrophysiological data. It is important to note that only three soundscape mixes were projected in the CVA as the control condition was calculated to measure the percentage change for each soundscape condition in terms of the electrophysiological measures. CVA is a multivariate analysis method that explores the relationship between groups of variables in a dataset. The CVA biplots in this study are plotted based on correlational basis to explore the relationship between temporal flavour, emotion, and ANS responses.

Additionally, the Hotelling-Lawley Multivariate Analysis of Variance (MANOVA) test was performed in order to determine whether significant differences existed between the three soundscape mixes in terms of standardized durations of flavour $(\alpha=.05) .90 \%$ confidence ellipses were also added to indicate the degree of significance between the sample centroids. CVA is used as it minimizes residual variability and maximizes the distances between the samples (Delarue \& Sieffermann, 2004). This method has been used in numerous TDS-based studies due to its robustness in discriminating between samples.

\subsubsection{Psychoacoustical analysis}

According to Zwicker and Fastl (2013), psychoacoustics parameters other than sound pressure levels can be used to describe a sound. These parameters include fluctuation strength, roughness, and sharpness. Fluctuation strength provides a measure of cyclic variations in amplitude modulation, roughness is a measure of lower frequency modulation $(15-300 \mathrm{~Hz})$, and sharpness is a measure of the relative content of high frequencies in a signal. All psychoacoustical analysis were carried out using the National Instruments LabVIEW 2013 software (Austin, TX, U.S.A). 


\section{Results}

\subsection{The effect of soundscapes on flavour perception}

Figure 1 shows the spline-smoothed TDS curves describing the dominance rate of various attributes of the chocolate ice-cream when consumed while listening to the café soundscape (control), and café soundscape mixed with one of the other soundscapes (i.e., bird, forest, and machine soundscapes). The results revealed that bitterness was always the final dominant attribute regardless of the soundscape that the participants were listening to. However, its dominance was dependent on the time of consumption at the later stages of consumption.

With the control café soundscape, cocoa was the dominant flavour from the beginning of consumption period until $27 \%$ standardized time (ST), increasing to a maximum dominance rate of $38 \%$ at $14 \%$ ST before declining. Bitterness was the next most dominant attribute, hovering between $23-33 \%$ dominance rate from $34-58 \% \mathrm{ST}$, whence it increased from $58 \%$ until the end of consumption period, reaching a maximum dominance rate of $59 \%$ at $99 \% \mathrm{ST}$.

When listening to the café-bird soundscape, cocoa was the dominant attribute until $2 \%$ ST. Creaminess was dominant from $3 \% \mathrm{ST}$, increasing to a maximum dominance rate of $41 \%$ at $10 \%$ ST, and then decreasing back to $18 \%$ ST. Bitterness was the next most dominant attribute from $53 \%$ ST until the end of consumption period with a maximum dominance rate of $43 \%$ after $90 \%$ ST.

For the cafe-forest soundscape, the first dominant attribute was creaminess between $0-13 \% \mathrm{ST}$, with a maximum dominance rate of $36 \%$ at $10 \% \mathrm{ST}$. Sweetness was dominant when listening to the cafe-forest soundscape from $10-23 \%$ with a maximum dominance rate of $35 \%$, compared to the other three soundscapes. Bitterness also had the longest duration from $22 \%$ ST until the end of the consumption period, reaching a maximum dominance rate of $43 \%$ at $91 \%$ ST when listening to the café-forest soundscape.

With the café-machine soundscape, attributes of sweetness ( $0-3 \% \mathrm{ST})$, creaminess (3-7\% ST), and cocoa $(7-9 \%$ ST) were the least dominant, and only reached a maximum dominance rate of $29 \%$. Bitterness was, in fact, the dominant attribute from 34\% ST until the end of consumption period, with increasing dominance until a maximum dominance rate of $57 \%$ at $98 \%$ ST was reached until the end of consumption. Although bitter was both dominant for both control café soundscape, and café-machine soundscape, the increase in bitterness occurred at different ST. 

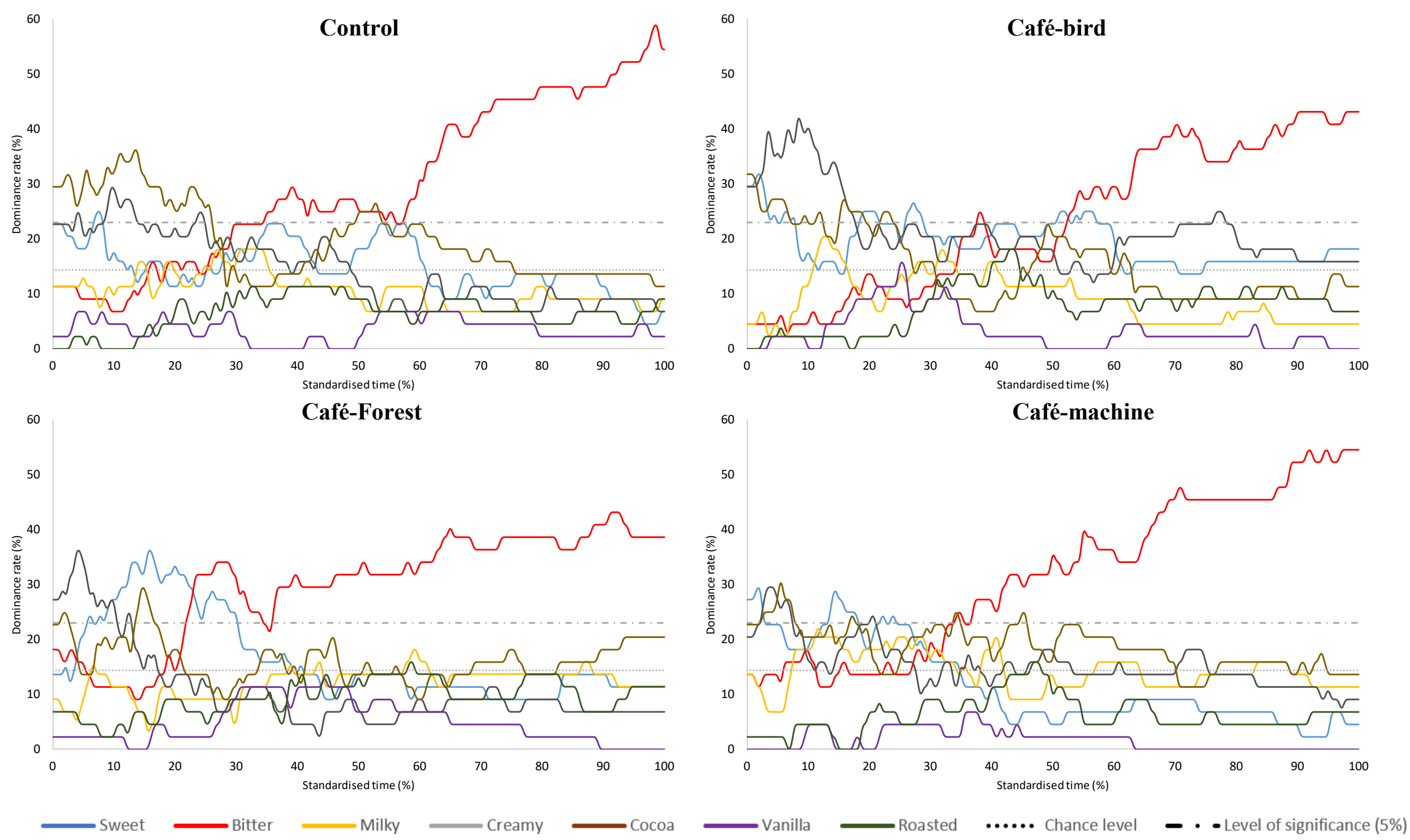
Figure 1: (Color online) Panel dominance rates (\%) of the seven sensory attributes presented in the TDS sessions expressed as \% of standardized time. TDS curves are for the four soundscapes. The calculated chance and significance levels were between $15 \%$ and $20 \%$, respectively, and attributes below $20 \%$ ( $r$ : significance level) are not considered. 


\subsection{The effect of soundscape on the flavour trajectories for the ice-cream}

Figure 2 represents a PCA to further scrutinize the effect of different soundscapes on the dominance rate of flavour over the standardized time of consumption. The first two PCA components accounted for $61 \%$ of the total variance explained. For each of four soundscapes, a trajectory of the dominant attributes present was plotted.

For the control café soundscape condition, cocoa was first perceived both at the start of consumption, specifically at $5 \%$ and $15 \%$ of the trajectory ST. Milky $(29 \%$ and $57 \%$ of the trajectory ST), vanilla $(30 \%$ and $58 \%$ of the trajectory ST), cocoa $(32 \%$ and $52 \%$ of the trajectory ST), creamy ( $33 \%$ and $52 \%$ of the trajectory ST) and sweet (34\% and $51 \%$ of the trajectory ST) flavours were further perceived during the early middle period of consumption. Roasted and bitter flavours were perceived at the later middle period of consumption, at $61 \%$ and $67 \%$ of the trajectory ST, respectively. A bitter note was again detected at the end of consumption, at $99 \%$ of the trajectory ST.

In the cafe-bird soundscape condition, creamy was first perceived from $0-12 \% \mathrm{ST}$ at the start of consumption. Then, the cocoa flavour was perceived at $14 \%, 17 \%$, and $22 \%$ of the trajectory ST. Milky and vanilla flavours were further perceived at 33\% and 34\% of the trajectory ST respectively. Creamy and sweet were perceived in the middle of consumption, both at about $45 \%$ and $50 \%$ of the trajectory ST.

In the café-forest soundscape condition, sweet taste/flavour was perceived at the beginning of consumption, at $0,9 \%, 13 \%$ and $20 \%$ of the trajectory times. This was followed by bitter notes and a roasted flavour. These were perceived at 31\% and 32\% of the trajectory ST respectively. Roasted flavour was further perceived at $61 \%$ onwards of the trajectory ST.

In the café-machine soundscape condition, creamy, sweet and cocoa flavours were perceived at the early period of consumption. Creamy flavour was perceived at $1 \%$ and $7 \%$, sweet flavour at $3 \%$ and $6 \%$, and cocoa flavour at $8 \%, 13 \%$, and $20 \%$ of the trajectory STs. This was followed by milky, vanilla, and roasted flavours, which were perceived at $36 \%, 37 \%$, and $44 \%$ of the trajectory ST, respectively. Roasted and bitter were further perceived during the middle of consumption, at 59\% and 61\% (roasted flavour), 65\% (bitter flavour) of the trajectory ST, respectively. The bitter note was mainly perceived at the end of consumption, at $81 \%$, and 90 $100 \%$ of the trajectory ST. 


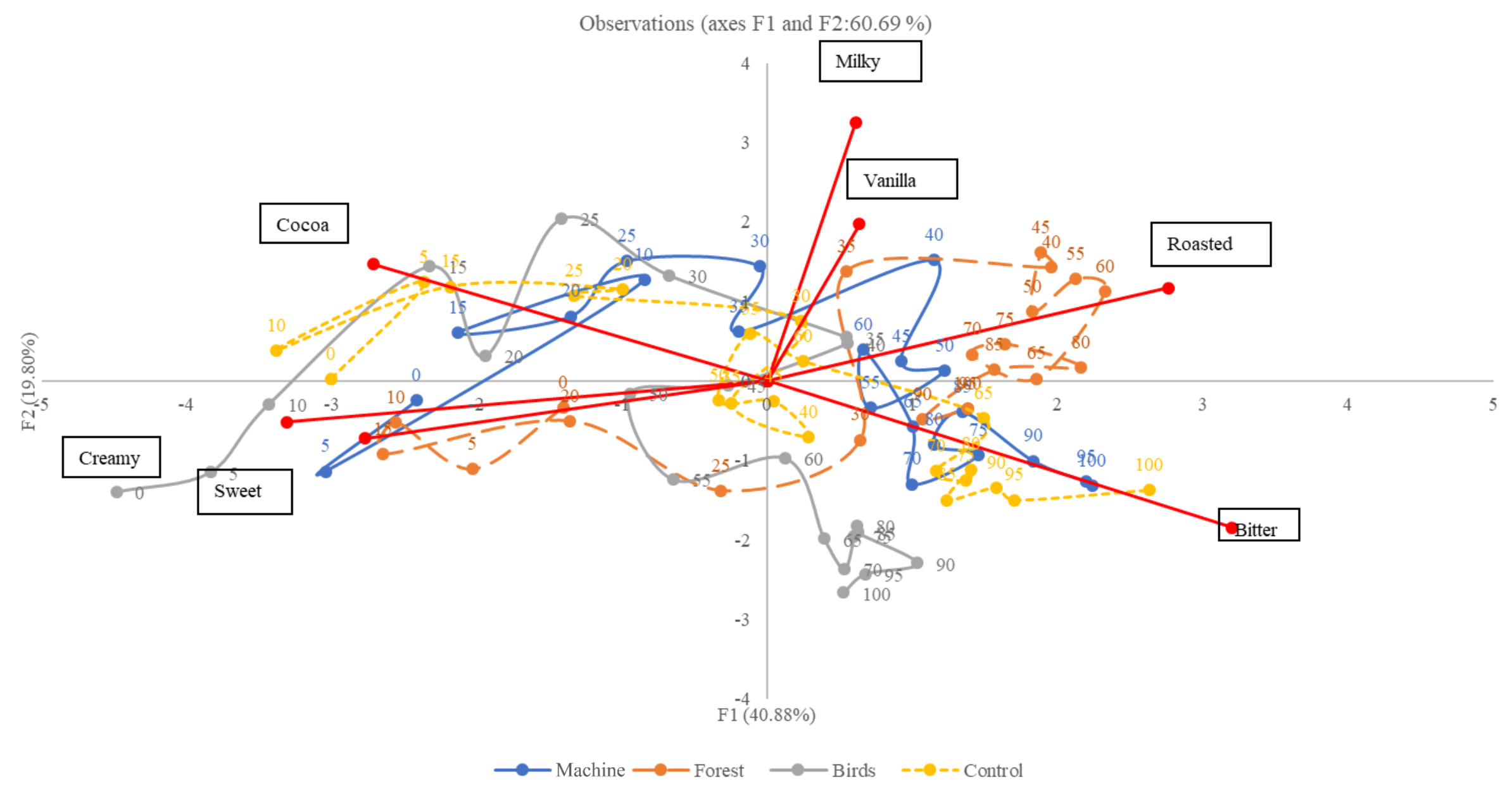

Figure 2: (Color online) Principal component analysis (PCA) biplot exhibiting the flavour trajectories of ice-cream consumed when listening to the control café, café-machine, café-forest and café-birds soundscape conditions. Vector points (red) represents the sensory attribute, while each soundscape (product) loadings were plotted for each 5\% TDS standardized trajectory period labelled 0-100. 


\subsection{The effect of soundscapes on emotional responses}

Participants rated their emotions while listening to the four different soundscapes after eating the ice-cream. Figure 3 shows that the four soundscapes were judged to be significantly different in all emotion terms measured, with the exception of surprise. The café-machine soundscape was rated significantly higher in terms of negative emotions like anger, disgust, disappointment and contempt as compared to the control cafe, café-bird and café-forest soundscapes. The café-forest and café-bird soundscapes, on the other hand, were significantly higher in terms of positive emotions such as amusement, happiness, enjoyment, love and satisfaction compared to the café-machine and control café soundscapes.

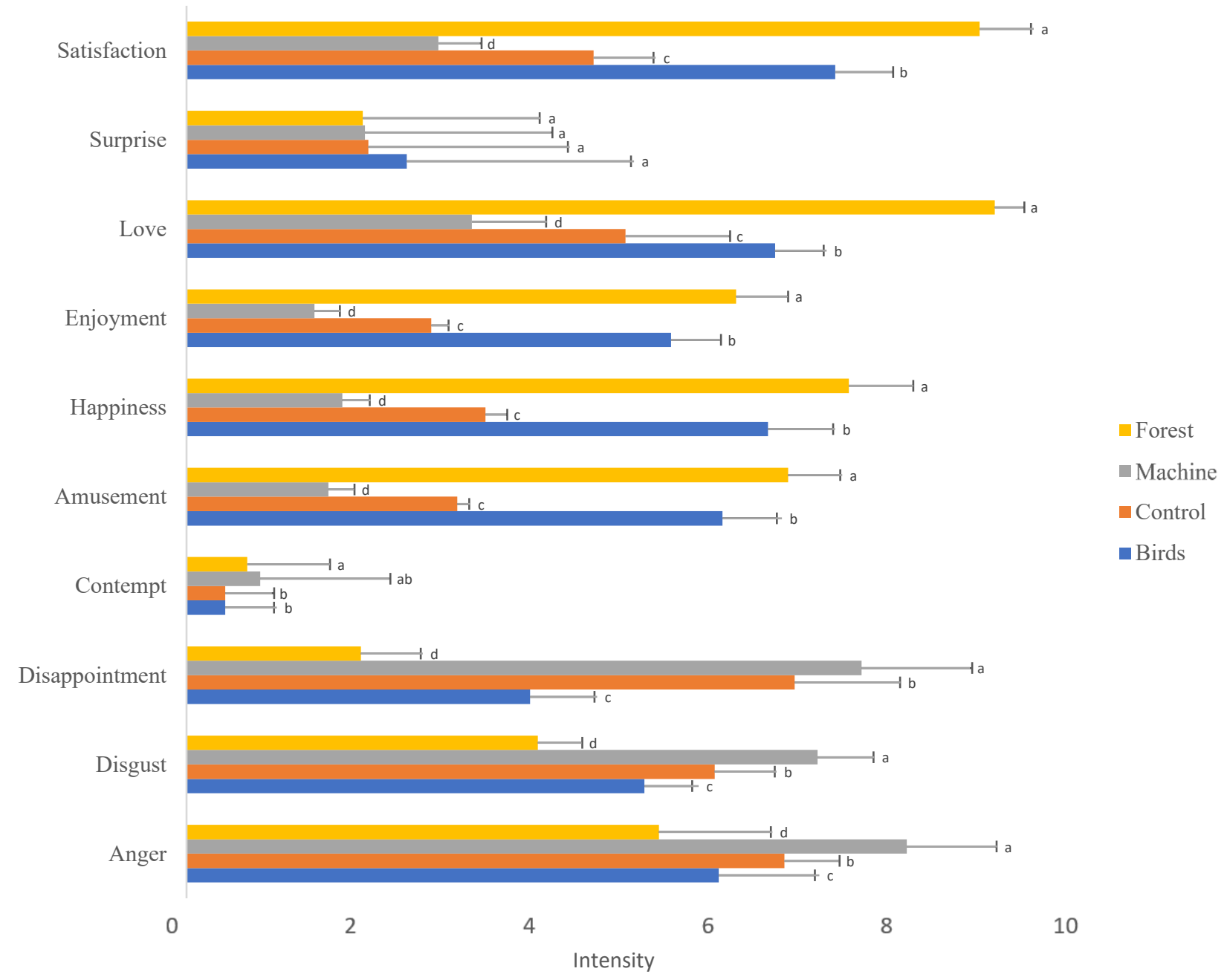

Figure 3: (Color online) Mean ratings of emotions when listening to different soundscapes (café-birds, café control, café-machine, and café-forest) after eating ice-cream. Mean emotion ratings of different soundscapes with different superscript letters ${ }^{(\mathrm{a}, \mathrm{b}, \mathrm{c}, \mathrm{d})}$ indicate significant differences in emotions ratings, while groups that share the same letter show no significant difference. Error bars illustrate the standard deviation for each soundscape condition. 


\subsection{The effect of soundscapes on electrophysiological responses}

The differences in electrophysiological responses between café and café mix soundscapes are shown in Figure 4. Listening to different soundscapes while eating ice-cream significantly influenced $\mathrm{HR}\left(\mathrm{F}_{(2,131)}=6820, \mathrm{p}<0.001\right), \mathrm{SC}\left(\mathrm{F}_{(2,131)}=1494, \mathrm{p}<0.001\right)$, BVP amplitude $\left(\mathrm{F}_{(2,131)}=\right.$ $3815, \mathrm{p}<0.001)$, and RESP $\left(\mathrm{F}_{(2,131)}=749, \mathrm{p}<0.001\right)$. HR, SC, and RESP were significantly higher when listening to the café-machine soundscape after eating ice-cream as compared to the café-forest and café-bird soundscapes. The BVP amplitude was significantly higher when listening to the café-forest soundscape while eating ice-cream as compared to the café-machine soundscape.

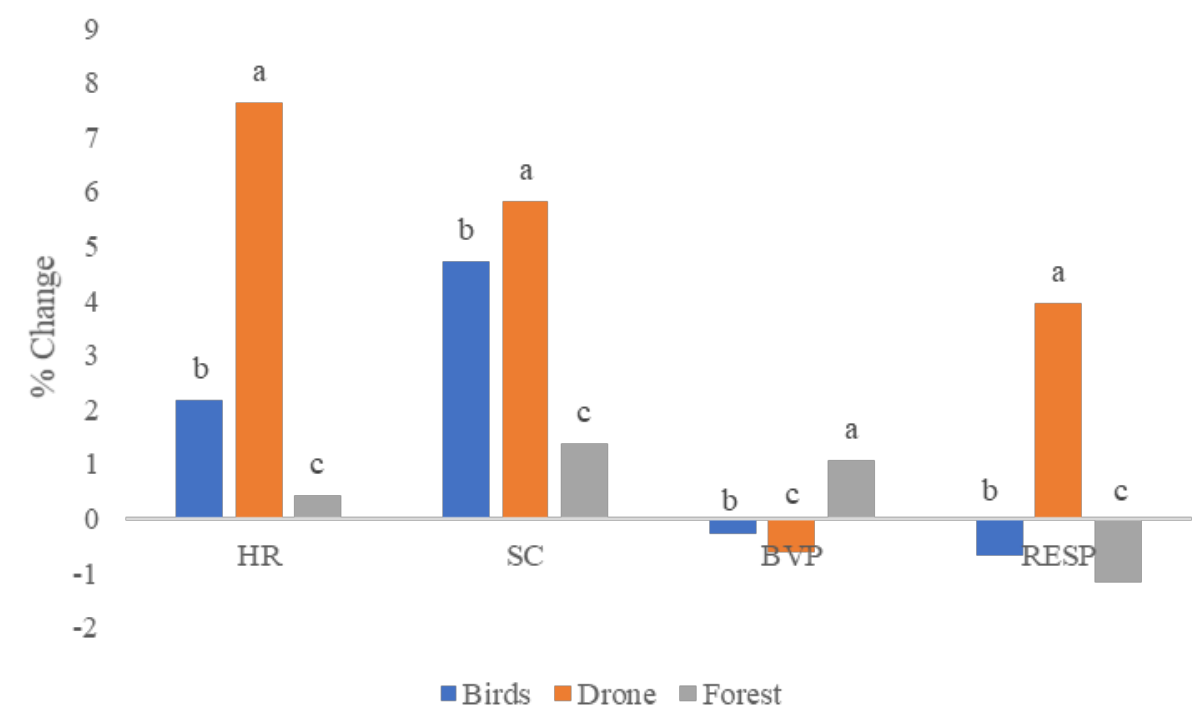

Figure 4: (Color online) Heart rate (HR), skin conductance (SC), blood volume pulse (BVP) amplitude, and respiration rate (RESP) values calculated based on changes in café-birds, café-machine and caféforest soundscapes compared to control café soundscape. Different superscript letters $\left({ }^{\mathrm{a}, \mathrm{b}, \mathrm{c}, \mathrm{d}}\right)$ indicate significant differences in physiological values using the Tukey's multiple comparison tests. 


\subsection{The relationship between sensory perception of ice-cream and emotional responses}

CVA was used to demonstrate the relationship between flavour, electrophysiology, and emotion responses while listening to the different soundscapes during the evaluation of icecream. Figure 5 reveals the first two canonical variates, which described $96.47 \%$ of the data. The $90 \%$ ellipse signifies the multidimensional confidence intervals of the means (Peltier, Visalli, \& Schlich, 2015) of the frequencies of emotions, electrophysiological, and multisensory flavour perception responses. The separation of the ellipses suggests that the flavour, electrophysiological, and emotional responses depended on the soundscapes that participants listened to during their consumption of the ice-cream.

The Hotelling-Lawley MANOVA analysis results showed significant differences between the flavour, electrophysiological, and emotional responses when listening to the different soundscapes after evaluating the ice-cream $\left(F_{(42,195)}=740.647, p<0.0001\right)$. The cafe-machine soundscape was associated with creamy and bitter attributes, negative emotions of anger, disappointment, disgust, and an increase in RESP and HR measures. The café-forest soundscape was strongly associated with higher loadings of sensory perception of sweet, positive emotions of love, satisfaction, happiness, amusement and enjoyment, and an increase in BVP amplitude compared to the café-bird soundscape, which had lower loadings of these measures.

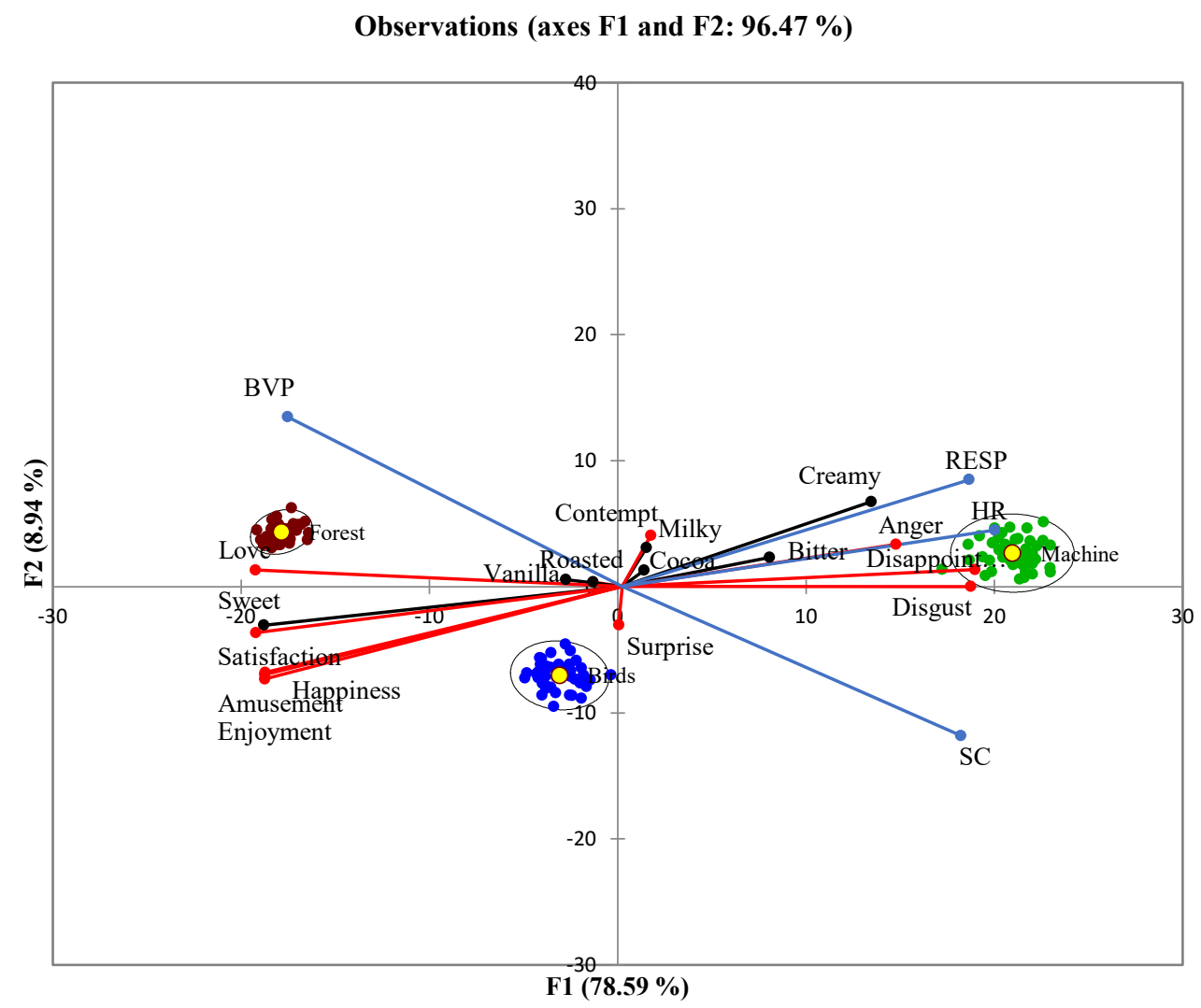

- Birds $\bullet$ Machine $\bullet$ Forest oCentroids 
Figure 5: (Color online) Joint CVA biplot of dominance durations of flavours, electrophysiological response, and emotion. Hotelling-Lawley MANOVA test showed significant product differences based on flavour attributes, electrophysiological, and emotion responses. To aid visualisation, positive and negative emotions are labelled in red, sensory attributes are labelled in black, and electrophysiological measures in blue. 90\%-confidence ellipses were added to indicate statistical significance. Nonoverlapping ellipses indicate soundscape-ice-cream sample centroid are significantly different, while overlapping ellipses suggest soundscape-ice-cream sample centroid are not significant. 


\subsection{Psychoacoustical properties of the soundscapes}

The café soundscape had the highest fluctuation strength, and lowest roughness and sharpness as compared to all other soundscapes. In contrast, the bird and forest soundscapes had higher sharpness compared to café and machine soundscapes.

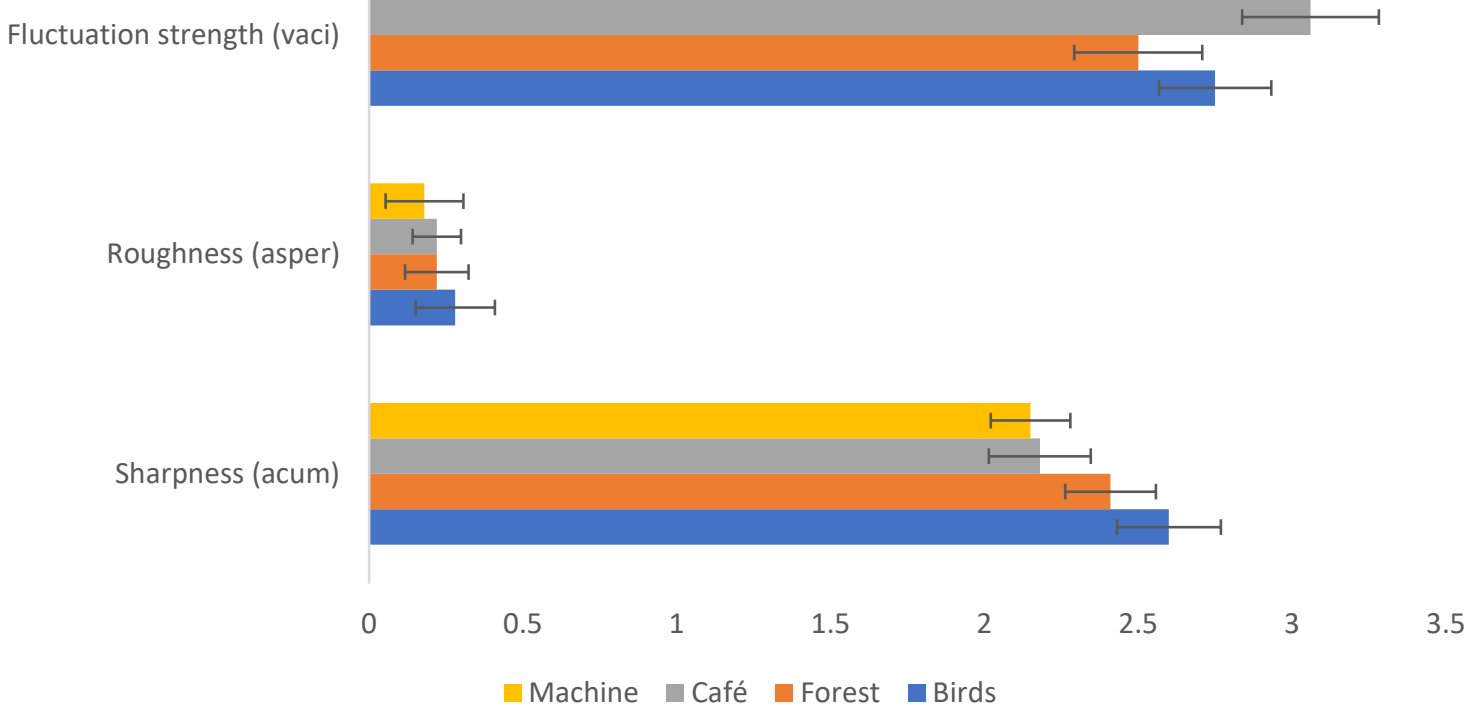

Figure 6: (Color online) Psychoacoustical properties of the four soundscapes used in the present study. Error bars represent standard deviations. 


\section{Discussion}

\subsection{Perception of ice-cream flavour varied when listening to the different}

mixed soundscapes

Crossmodal studies investigating interactions between soundscapes and flavour perception are increasingly appearing in the literature (Velasco, Jones, King, \& Spence, 2013). Recently, for example, Wang and Spence (2018) have demonstrated that soundscape properties such as tonality and pitch influence the sensory judgments of wine professionals. For example, playing a 'sweet' soundtrack increased the perceived sweetness of wine, while playing a 'sour' soundtrack increased the perception of sourness. Wang et al. (2017) have also successfully manipulated perceptions of spiciness by creating a high pitched, fast tempo, and highly distorted 'spicy' soundtrack.

The present study demonstrated that panellists' perception of an ice-cream changed when tasting while listening to different mixed background soundscapes. The flavour changes in icecream while listening to control café, café-machine, café-forest, and café-bird soundscapes were further confirmed using trajectory plots. When listening to the café-forest soundscape, sweetness was more dominant and for a longer ST duration at the start of consumption as compared to either the café-bird and café-machine soundscapes. Crisinel et al. (2012) reported that sweetness was positively correlated with a 'sweet' (i.e., higher-pitched soundscape) when consuming cinder toffee. Likewise, it has been reported that higher and longer dominance rates of sweetness were perceived when the participants listened to liked music at the start of consumption when consuming bittersweet (Kantono et al., 2018) and milk (Kantono, Hamid, Shepherd, Yoo, et al., 2016) gelato compared to disliked and neutral music. Similarly, ReinosoCarvalho et al. (2017) reported that chocolates tasted sweeter while listening to the 'creamy' soundtrack that participants liked significantly more than the 'rough' soundtrack.

When listening to the café-bird and café-forest soundscapes, creaminess was dominant at a higher dominance rate and longer ST duration at the start of ice-cream consumption as compared to the café-machine soundscape. The finding is consistent with the findings reported by Reinoso-Carvalho et al. (2017). The latter researchers described how listening to a 'creamy' soundtrack enhanced the perceived creaminess of chocolate. The 'creamy' soundtrack described in their study comprised of a loop-ascending scale of consonant-long flute notes, mixed with large hall reverberation. The authors also demonstrated a clear correlation between soundtrack liking and chocolate liking and suggested that the increased creaminess might be due to sensation transference effect. In addition, music-elicited emotion has been shown to transfer to the subsequent processing of facial expressions (Logeswaran \& Bhattacharya, 2009) and the perception of sensual touch (Fritz et al., 2017). In the present study, positive emotions were evoked in those participants who listened to the café-bird and café-forest soundscapes. Hence, the increase in creaminess dominance in our study can be explained by the sensation transference mechanism where soundscapes that evoked positive emotions may increase creaminess perception.

In this study, a higher dominance rate of bitterness was perceived at the end of the consumption period when listening to the café control and café-machine soundscapes ascompared to the café-birds and café-forest soundscapes. Crisinel et al. (2012) reported that the perceived bitterness of cinder toffee was positively correlated to a low-pitched 'bitter' soundtrack. In 
addition, Reinoso Carvalho et al. (2017) found that chocolates were rated as tasting more bitter while listening to the less liked 'rough' soundtrack that consisted of a loop-ascending scale of three blended dissonant-dry pizzicato short violin lines. Furthermore, a higher dominance rate of bitterness was perceived at the end of the consumption period when listening to disliked music when consuming bittersweet and dark chocolate gelato compared to liked music was reported by (Kantono, Hamid, Shepherd, Yoo, et al., 2016).

\subsection{Emotions varied when listening to the different soundscapes}

Consistent with the circumplex model of emotion (Russell, 1980; Russell \& Pratt, 1980), in the present study, negative emotions such as anger, disgust, disappointment, and contempt were dependent upon soundscape type. Specifically, negative emotions were rated significantly higher when listening to the machine soundscape compared to the control, birds, and forest soundscapes. Some studies have reported that noise and disliked music are typically related to negative emotions. For example, Özcan and van Egmond (2012) demonstrated that machine soundscapes were associated with unpleasant emotions, while Medvedev et al. (2015) reported that dominance and eventfulness ratings were higher when listening to construction, motorbike, airplane and road traffic soundscapes as compared to birdsong and forest soundscapes. Noise annoyance, a negative emotion was further found to be positively and significantly associated with the railway and road traffic noise (Urban \& Máca, 2013) and wind turbine noise (Pedersen \& Larsman, 2008). Paunović et al. (2014) also indicated that noise annoyance was significantly increased when listening to noise associated with public transport. Kantono et al. (2019) found that negative emotions like disappointment, disgust, and contempt were rated significantly higher when listening to disliked music after eating chocolate gelato as compared to the liked, neutral and silent music conditions.

Positive emotions such as amusement, happiness, enjoyment, love, and satisfaction were significantly higher when listening to the café-forest and café-bird soundscapes as compared to when listening to the café-machine and control café soundscapes. This result is to be expected given the many studies that have revealed that natural soundscapes are associated with positive emotions. Medvedev et al. (2015) reported that the pleasantness ratings were significantly higher for ocean and bird song soundscapes compared to construction, road traffic, motorbike and airplane soundscapes. The valence ratings were also significantly higher when listening to the café soundscape after consuming chocolate ice-cream compared to fast food, bar, and laboratory soundscapes (Kantono, Hamid, Shepherd, Lin, Yakuncheva, et al., 2016). Kantono et al. (2016a) further reported that the positive emotions like amusement, happiness, enjoyment, love, satisfaction, and pleasantness were rated significantly higher while listening to liked music compared to the disliked music when consuming chocolate gelato. In conclusion, annoying soundscapes like the café-machine soundscape were associated with higher ratings of negative emotions, while the café-forest soundscape had the highest ratings of positive emotions.

\subsection{Electrophysiological responses vary when listening to different soundscapes}

The influence of soundscapes on electrophysiological responses has been widely researched (Van Kamp \& Davies, 2008). However, in most previous studies, electrophysiological responses to soundscapes have been measured in isolation and without any food being 
consumed. In this study, electrophysiological measures of HR and SC were correlated with listening to the café-machine soundscape while eating ice-cream compared to the café-forest and café-birds soundscapes. Gomez and Danuser (2004) showed that HR and SC significantly increased when listening to high-arousal (e.g., mechanical soundscapes) compared to lowarousal (e.g., birds chirping) noises. Belojevic et al. (2008) reported that the HR of children was significantly higher in noisy residential areas as compared to quiet residential areas and kindergartens. Medvedev et al. (2015) further demonstrated that HR and SC were significantly higher when listening to the construction and road traffic soundscapes as compared to birdsong and ocean soundscapes. In addition, SC significantly increased when listening to a noise environment compared to nature soundscape (Alvarsson et al. (2010). Kantono et al. (2019) further reported that $\mathrm{SC}$ was significantly higher when listening to disliked music compared to neutral and liked music while consuming gelato. These findings are consistent with the notion that highly arousing soundscapes, irrespective of their valence, stimulate the sympathetic branch of the autonomic nervous system. The SC response involves rapid fluctuations in eccrine sweat gland activity as a result of acetylcholine release by the sympathetic nervous system.

In the present study, respiration rate was significantly higher when listening to the cafémachine soundscape while eating ice-cream compared to the café-forest and café-birds soundscapes. Gomez and Danuser (2004) revealed that the respiration rate was higher when listening to high-arousal noises compared to low-arousal noises. Etzel et al. (2006) also reported that the respiration rate was significantly higher when listening to fearful and happy music compared to sad music.

The BVP amplitude was significantly higher when listening to the café-forest soundscapes while eating ice-cream compared to the café-machine soundscape in the present study. This suggests that listening to café-forest soundscape decreases arousal, as higher BVP amplitude tends to be associated with calmer states. Krzywicka and Byrka (2017) demonstrated that relaxation significantly increased when listening to the natural soundscapes compared to urban soundscapes. Our results also concord with findings by Yanagihashi, Ohira, Kimura, and Fujiwara (1997). The latter demonstrated that listening to a pleasant bird chirping soundscape activated a parasympathetic nervous system response, one that is associated with an increase in the BVP response (Kreibig et al., 2007).

\subsection{The relationship between flavour, electrophysiological, and emotional responses under different soundscape conditions}

The present study explored how emotions and electrophysiological measures may help explain changes in sensory perception when listening to the different soundscapes. The current study provides evidence on the role of emotions in mediating the crossmodal correspondence between sounds and flavours. For example, negative emotions such as anger, disgust, and disappointment evoked while listening to cafe-machine sounds, were found to be correlated with bitterness and creaminess. On the other hand, listening to cafe-forest sounds evoked positive emotions of satisfaction, happiness, amusement, enjoyment, and love, were correlated with sweetness. This was in-line with previous studies that have demonstrated the influence of emotions on food perception. Negative emotions (e.g., disgust, boredom) have been reported to be associated with bitterness in chocolate ice-cream (Kantono et al., 2016b) and 70\% cocoa 
chocolate (Jager et al., 2014). A recent study by Motoki and Sugiura (2018) also showed that negative emotions (i.e., disgust) decreased food preferences. On the other hand, positive emotions (e.g., happiness, satisfaction) were found to be correlated with sweetness and milkiness of chocolate ice-cream (Kantono et al., 2016b), sweetness of orange and blueberry chocolate (Jager et al., 2014), as well as sweetness and cocoaness in chocolate (Thomson et al., 2010). Recently, Reinoso-Carvalho, Dakduk, Wagemans \& Spence (2019) reported that emotional reactions triggered by the music influenced specific sensory aspects of beer. Participants liked the beer more, and rated it sweeter, when listening to music associated with positive emotion. The same beer was rated as more bitter, with higher alcohol content, and as having more body, when the participants listened to music associated with negative emotion. The sensation transference mechanism has been used to explain the changes in these sensory responses due to changes in emotion. Spence, Velasco, and Knoeferle (2014) and Spence and Wang (2015) suggested that listening to music may put the listener into a certain mood (e.g., good or bad), which can influence the perception and appreciation of wine. This effect was also evident in the evaluation of beers while listening to different soundscapes (Carvalho, Wang, Van Ee, \& Spence, 2016). They found that listening to a pleasant soundscape evoked higher pleasantness and sweetness ratings and hedonic and taste liking of beer.

Crossmodal correspondences between sound components and taste/flavour have been reported. Pitch has been found to be associated with specific taste (e.g. high pitch to sweetness) (Spence, Reinoso-Carvalho, Velasco, \& Wang, 2019), and recently been reported to influence purchase intent (Motoki, Saito, Nouchi, Kawashima, \& Sugiura, 2018). Interestingly, psychoacoustical results in this study revealed that the machine soundscape had lower sharpness than bird and forest soundscapes (Section 3.6) and was correlated to bitter that evoked negative emotions (Section 3.3). Interestingly, Knoeferle et al. (2015) reported that taste mappings in the auditory sharpness dimension did not follow a hedonic matching account. They demonstrated that participants mapped the more unpleasant bitter taste onto more pleasant sounds that were low in auditory sharpness, but the sour sound to more unpleasant sounds with higher auditory sharpness. However in their study, participants were only asked to match selected auditory parameters of an experimental sound to basic taste words. In this study, participants consumed ice-cream and rated sensory perception over time while listening to the different soundscapes. The most interesting finding to emerge from this study was the fact that emotions were associated with changes in electrophysiological measures that influenced perceived flavour of ice-cream. Listening to the café-machine soundscape elicited perceptions of bitter and creamy, and evoked negative emotions associated with increased RESP and HR. Kantono et al. (2019) similarly concluded that negative emotions were positively associated with HR, thus replicating the findings of Medvedev et al. (2015). Negative emotions have also been associated with increases in RESP. Bloch, Lemeignan, and Aguilera-T (1991) mentioned that RESP rate was significantly higher when anger emotion was experienced compared to joy. Similarly, Etzel et al. (2006) found that the increase in RESP rate was related to the negative emotion of sadness when listening to sad music. Another important finding to emerge from the present study was that listening to the café-forest soundscape was associated with sweetness perception evoked positive emotions that, in turn, coincided with BVP amplitude. Positive emotions were positively associated with sweetness in chocolate gelato (Kantono et al., 2016c) and chocolate (Jager et al., 2014; Thomson, Crocker, and Marketo (2010). Kantono et al. (2019) and Trochidis, Sears, Trân, and McAdams (2012) further demonstrated that the BVP amplitude was positively associated with positive emotions when listening to music. Listening to pleasurable music has been shown to increase BVP amplitude (Salimpoor et al., 2011). 
This study confirms that the sensation transference mechanism may explain the changes in flavour when consuming ice-cream under different soundscape conditions. Perhaps the most important finding in this study was that emotions elicited from listening to different overlaid soundscapes were transferred to subsequent perception of flavour. These emotions were found to be strongly associated with flavour perception when listening to different overlaid café soundscapes emphasizing the importance of monitoring ANS responses, as they provide an objective measure linked to emotions. Kreibig et al. (2007) demonstrated that ANS measurements can generate specific responses (e.g., an increase in HR together with a decrease in BVP) to appraise specific emotions. Interestingly, Meiselman (2017) reported that facial scaling and autonomic measures might be worth exploring to understand emotions better.

\section{Conclusions}

The present study investigated how various background soundscapes can influence taste/flavour perception, emotions, and electrophysiological states of participants during the consumption of ice-cream. The most salient finding to emerge from the present study is that the consumption of ice-cream while listening to different café soundscapes mixed with other soundscapes had an effect on the temporal aspects of flavour perception, as well as emotional and electrophysiological responses. The different soundscape mixes clearly influenced the participants' emotional state, as reflected in the significant changes in HR, SC, RESP, and BVP amplitude. The current findings highlight the importance of measuring electrophysiological responses of individuals during food consumption in order to further explain temporal changes in multisensory flavour perception. It is interesting to note how gastronomy chefs have intuitively used nature soundscapes when serving dishes to enhance the naturalness of the dish to enhance the eating experience (see: the Sounds of the Sea dish by Heston Blumenthal (Blumenthal, 2007, 2008). It is recommended that further studies be carried out to determine how consumption of food under different nature soundscapes (e.g., sea, park) in real eating environments can influence temporal flavour perception. This information can be used to assess targeted interventions aimed at improving food perception in real environments by modulating soundscape conditions.

\section{Acknowledgments}

The authors would like to acknowledge the School of Science at AUT for the Performance Based Research Fund (PBRF) to support this research. 


\section{References}

Aguinis, H., \& Harden, E. E. (2009). Sample size rules of thumb: Routledge: New York.

Alvarsson, J. J., Wiens, S., \& Nilsson, M. E. (2010). Stress recovery during exposure to nature sound and environmental noise. International Journal of Environmental Research and Public Health, 7(3), 1036-1046.

Belojevic, G., Jakovljevic, B., Paunovic, K., Ilic, J., \& Stojanov, V. (2008). Urban road-traffic noise and blood pressure and heart rate in preschool children. Environment International, 34(2), 226-231.

Bloch, S., Lemeignan, M., \& Aguilera-T, N. (1991). Specific respiratory patterns distinguish among human basic emotions. International Journal of Psychophysiology, 11(2), 141154.

Blumenthal, H. (2007). Further adventures in search of perfection: Reinventing kitchen classics: Bloomsbury Publishing.

Blumenthal, H. (2008). The big fat duck cookbook: Bloomsbury.

Carvalho, F. R., Wang, Q. J., van Ee, R., Persoone, D., \& Spence, C. (2017). "Smooth operator": Music modulates the perceived creaminess, sweetness, and bitterness of chocolate. Appetite, 108, 383-390.

Carvalho, F. R., Wang, Q. J., Van Ee, R., \& Spence, C. (2016). The influence of soundscapes on the perception and evaluation of beers. Food Quality and Preference, 52, 32-41.

Crisinel, A.-S. (2010). As bitter as a trombone: Synesthetic correspondences in nonsynesthetes between tastes/flavors and musical notes. Attention, Perception, \& Psychophysics, 72(7), 1994-2002.

Crisinel, A.-S., Cosser, S., King, S., Jones, R., Petrie, J., \& Spence, C. (2012). A bittersweet symphony: systematically modulating the taste of food by changing the sonic properties of the soundtrack playing in the background. Food Quality and Preference, 24(1), 201204.

Delarue, J., \& Sieffermann, J.-M. (2004). Sensory mapping using Flash profile. Comparison with a conventional descriptive method for the evaluation of the flavour of fruit dairy products. Food Quality and Preference, 15(4), 383-392.

Demattè, M. L., Pojer, N., Endrizzi, I., Corollaro, M. L., Betta, E., Aprea, E., . . . Gasperi, F. (2014). Effects of the sound of the bite on apple perceived crispness and hardness. Food Quality and Preference, 38, 58-64.

Eifert, G. H., Craill, L., Carey, E., \& O'Connor, C. (1988). Affect modification through evaluative conditioning with music. Behaviour Research and Therapy, 26(4), 321-330.

Etzel, J., Johnsen, E., Dickerson, J., Tranel, D., \& Adolphs, R. (2006). Cardiovascular and respiratory responses during musical mood induction. International Journal of Psychophysiology, 61(1), 57-69.

Frith, C. D., \& Allen, H. A. (1983). The skin conductance orienting response as an index of attention. Biological Psychology, 17(1), 27-39.

Gomez, P., \& Danuser, B. (2004). Affective and physiological responses to environmental noises and music. International Journal of Psychophysiology, 53(2), 91-103.

Kantono, K., Hamid, N., Shepherd, D., Lin, Y. H. T., Brard, C., Grazioli, G., \& Carr, B. T. (2018). The effect of music on gelato perception in different eating contexts. Food Research International, 113, 43-56.

Kantono, K., Hamid, N., Shepherd, D., Lin, Y. H. T., Skiredj, S., \& Carr, B. T. (2019). Emotional and electrophysiological measures correlate to flavour perception in the presence of music. Physiology \& Behavior, 199, 154-164.

Kantono, K., Hamid, N., Shepherd, D., Lin, Y. H. T., Yakuncheva, S., Yoo, M. J., . . Carr, B. 
T. (2016). The influence of auditory and visual stimuli on the pleasantness of chocolate gelati. Food Quality and Preference, 53, 9-18.

Kantono, K., Hamid, N., Shepherd, D., Lin, Y. H. T., Yoo, M. J., Grazioli, G., \& Carr, B. T. (2016). Listening to music can influence hedonic and sensory perceptions of gelati. Appetite, 100, 244-255.

Kantono, K., Hamid, N., Shepherd, D., Yoo, M. J., Grazioli, G., \& Carr, B. T. (2016). Listening to music can influence hedonic and sensory perceptions of gelati. Appetite, 100, 244255.

Kreibig, S. D., Wilhelm, F. H., Roth, W. T., \& Gross, J. J. (2007). Cardiovascular, electrodermal, and respiratory response patterns to fear-and sadness-inducing films. Psychophysiology, 44(5), 787-806.

Krzywicka, P., \& Byrka, K. (2017). Restorative qualities of and preference for natural and urban soundscapes. Frontiers in Psychology, 8, 1705.

Labbe, D., Schlich, P., Pineau, N., Gilbert, F., \& Martin, N. (2009). Temporal dominance of sensations and sensory profiling: A comparative study. Food Quality and Preference, 20(3), 216-221.

Laumann, K., Garling, T., \& Stormark, K. M. (2003). Selective attention and heart rate responses to natural and urban environments. Journal of Environmental Psychology, $23,125-134$.

Medvedev, O., Shepherd, D., \& Hautus, M. J. (2015). The restorative potential of soundscapes: A physiological investigation. Applied Acoustics, 96, 20-26.

Meiselman, H. L. (2017). Emotion measurement: Theoretically pure or practical? Food Quality and Preference, 62, 374-375.

Motoki, K., Saito, T., Nouchi, R., Kawashima, R., \& Sugiura, M. (2019). A Sweet Voice: The Influence of Cross-Modal Correspondences Between Taste and Vocal Pitch on Advertising Effectiveness. Multisensory research, 32(4-5), 401-427.

Motoki, K., \& Sugiura, M. (2018). Disgust, sadness, and appraisal: Disgusted consumers dislike food more than sad ones. Frontiers in Psychology, 9, 76.

Özcan, E., \& van Egmond, R. (2012). Basic semantics of product sounds. International Journal of Design, 6(2).

Paunović, K., Belojević, G., \& Jakovljević, B. (2013). Blood pressure of urban school children in relation to road-traffic noise, traffic density and presence of public transport. Noise and Health, 15(65), 253.

Paunović, K., Belojević, G., \& Jakovljević, B. (2014). Noise annoyance is related to the presence of urban public transport. Science of the Total Environment, 481, 479-487.

Pedersen, E., \& Larsman, P. (2008). The impact of visual factors on noise annoyance among people living in the vicinity of wind turbines. Journal of Environmental Psychology, 28(4), 379-389.

Pedersen, E., \& Waye, K. P. (2007). Wind turbine noise, annoyance and self-reported health and wellbeing in different living environments. Occupational Environmental Medicine.

Peltier, C., Visalli, M., \& Schlich, P. (2015). Canonical variate analysis of sensory profiling data. Journal of Sensory Studies, 30(4), 316-328.

Pineau, N., Schlich, P., Cordelle, S., Mathonnière, C., Issanchou, S., Imbert, A., . . Köster, E. (2009). Temporal Dominance of Sensations: Construction of the TDS curves and comparison with time-intensity. Food Quality and Preference, 20(6), 450-455.

Rahne, T., Köppke, R., Nehring, M., Plontke, S. K., \& Fischer, H.-G. (2018). Does ambient noise or hypobaric atmosphere influence olfactory and gustatory function? PloS ONE, 13(1), e0190837.

Russell, J. A. (1980). A circumplex model of affect. Journal of Personality and Social Psychology, 39(6), 1161. 
Russell, J. A., \& Pratt, G. (1980). A description of the affective quality attributed to environments. Journal of Personality and Social Psychology, 38(2), 311.

Saint-Eve, A., Panouille, M., Capitaine, C., Deleris, I., \& Souchon, I. (2015). Dynamic aspects of texture perception during cheese consumption and relationship with bolus properties. Food Hydrocolloids, 46, 144-152.

Salimpoor, V. N., Benovoy, M., Larcher, K., Dagher, A., \& Zatorre, R. J. (2011). Anatomically distinct dopamine release during anticipation and experience of peak emotion to music. Nature Neuroscience, 14(2), 257.

Seo, H.-S., Gudziol, V., Hähner, A., \& Hummel, T. (2011). Background sound modulates the performance of odor discrimination task. Experimental Brain Research, 212(2), 305314.

Seo, H.-S., Hähner, A., Gudziol, V., Scheibe, M., \& Hummel, T. (2012). Influence of background noise on the performance in the odor sensitivity task: effects of noise type and extraversion. Experimental Brain Research, 222(1-2), 89-97.

Seo, H.-S., \& Hummel, T. (2010). Auditory-olfactory integration: congruent or pleasant sounds amplify odor pleasantness. Chemical Senses, 36(3), 301-309.

Shepherd, D., Hautus, M. J., Lee, J., \& Mulgrave, J. (2014). Four electrophysiological studies into noise sensitivity. Institute of Noise Control Engineering. Symposium conducted at the meeting of the INTER-NOISE and NOISE-CON Congress and Conference Proceedings

Spence, C. (2014). Noise and its impact on the perception of food and drink. Flavour, 3(1), 9.

Spence, C., Reinoso-Carvalho, F., Velasco, C., \& Wang, Q. J. (2019). Extrinsic Auditory Contributions to Food Perception \& Consumer Behaviour: an Interdisciplinary Review. Multisensory research, 1-44.

Spence, C., Shankar, M. U., \& Blumenthal, H. (2011). Sound bites': Auditory contributions to the perception and consumption of food and drink. Art and the Senses, 207-238.

Spence, C., Velasco, C., \& Knoeferle, K. (2014). A large sample study on the influence of the multisensory environment on the wine drinking experience. Flavour, 3(1), 8.

Spence, C., \& Wang, Q. J. (2015). Wine and music (II): can you taste the music? Modulating the experience of wine through music and sound. Flavour, 4(1), 33.

Stafford, L. D., Fernandes, M., \& Agobiani, E. (2012). Effects of noise and distraction on alcohol perception. Food Quality and Preference, 24(1), 218-224.

Thomson, D. M., Crocker, C., \& Marketo, C. G. (2010). Linking sensory characteristics to emotions: An example using dark chocolate. Food Quality and Preference, 21(8), 1117-1125.

Trochidis, K., Sears, D., Trân, D.-L., \& McAdams, S. (2012). Psychophysiological measures of emotional response to Romantic orchestral music and their musical and acoustic correlates. Springer. Symposium conducted at the meeting of the International Symposium on Computer Music Modeling and Retrieval

Urban, J., \& Máca, V. (2013). Linking traffic noise, noise annoyance and life satisfaction: A case study. International Journal of Environmental Research and Public Health, 10(5), 1895-1915.

Van Kamp, I., \& Davies, H. (2008). Environmental noise and mental health: Five year review and future directions. Symposium conducted at the meeting of the Proceedings of the 9th international congress on noise as a public health problem

Wang, Q., \& Spence, C. (2018). Assessing the influence of music on wine perception among wine professionals. Food Science \& Nutrition, 6(2), 295-301.

Woods, A., Poliakoff, E., Lloyd, D., Kuenzel, J., Hodson, R., Gonda, H., . . . Thomas, A. (2011). Effect of background noise on food perception. Food Quality and Preference, $22(1), 42-47$. 
Xu, Y., Hamid, N., Shepherd, D., Kantono, K., \& Spence, C. (2019). Changes in flavour, emotion, and electrophysiological measurements when consuming chocolate ice cream in different eating environments. Food Quality and Preference, 77, 191-205.

Yanagihashi, R., Ohira, M., Kimura, T., \& Fujiwara, T. (1997). Physiological and psychological assessment of sound. International Journal of Biometeorology, 40(3), 157-161.

Zampini, M., \& Spence, C. (2004). The role of auditory cues in modulating the perceived crispness and staleness of potato chips. Journal of Sensory Studies, 19(5), 347-363.

Zwicker, E., \& Fastl, H. (2013). Psychoacoustics: Facts and models (Vol. 22): Springer Science \& Business Media. 